\title{
An aqueous extract of Liu Wei Di Huang Wan alters the labeling of blood constituents with Technetium-99m
}

\author{
MATOS Verônica Soares de, CARMO Fernanda Santos do*, DINIZ Claudia Leite, \\ NASCIMENTO Ana Lucia Rosa, PEREIRA Márcia Oliveira, \\ FERNANDES Joelma Fonseca de Oliveira, SANTOS-FILHO Sebastião David, \\ MORENO Silvana Ramos Farias \& BERNARDO-FILHO Mario
}

Departamento de Biofísica e Biometria, Instituto de Biologia Roberto Alcantara Gomes, Universidade do Estado do Rio de Janeiro, Av. 28 de Setembro, 87, Rio de Janeiro, RJ 20551-030, Brasil

Received November 28, 2012; accepted February 6, 2013; published online April 7, 2013

\begin{abstract}
The Liu Wei Di Huang Wan is a formula of a traditional Chinese medicine that is used to treat asthma patients and has been shown to have several important properties, such as antioxidant and free radical scavenging activities. The influence of an extract of Liu Wei Di Huang Wan on the labeling of blood constituents with technetium-99m was investigated. Anticoagulated blood (Wistar rats) was incubated with the extract, stannous chloride and technetium-99m, as sodium pertechnetate. Samples were centrifuged and aliquots of plasma and blood cells were separated and precipitated with trichloroacetic acid, to obtain soluble and insoluble fractions of the blood constituents. The percentage of radioactivity (\%ATI) in all the fractions was determined. The analysis of the results shows that the extract at the highest concentration used $(70 \mathrm{mg} / \mathrm{mL})$ decreased significantly $(P<0.05)$ the \%ATI (from $96.48 \pm 1.19$ to $54.46 \pm 7.38$ ) on blood cells compartment, (from $81.11 \pm 4.15$ to $61.33 \pm 4.74$ ) on insoluble fractions of blood cells and (from $65.91 \pm 2.44$ to $13.15 \pm 3.62$ ) on insoluble fractions of plasma. In conclusion, the results suggest that the substances present on this extract can alter this labeling process, probably due to (i) redox properties (antioxidant and chelator activities) and/or (ii) specific actions in the binding sites where the $99 \mathrm{mTc}$ would be bound on the blood constituents. As a consequence, precaution is suggested on the interpretation of the nuclear medicine results from performed with blood constituents labeled with ${ }^{99 \mathrm{~m}} \mathrm{Tc}$ in patients that have undertaken LWDHW, although the current findings were obtained in experimental animal models.
\end{abstract}

Liu Wei Di Huang Wan, technetium-99m, blood constituents, traditional Chinese medicine

Citation: Matos V S de, Carmo F S do, Diniz C L, et al. An aqueous extract of Liu Wei Di Huang Wan alters the labeling of blood constituents with Technetium-99m . Chin Sci Bull, 2013, 58: 2061-2065, doi: 10.1007/s11434-013-5778-2

The consumption of natural products, as food, additives or medications to treat different diseases has grown all over the world [1,2]. These products are used by individuals, often for a long time, in natura or in the form of pharmaceutical preparations of vegetal structures, such as leaves, rhizomes, roots, flowers and seeds [3] for the prevention and treatment of human disease [4]. In addition, many pharmaceuticals approved by the Food and Drug Administration have their origins in plants. Moreover, various investiga-

*Corresponding author (email: fernandacarmo10@yahoo.com.br) tions have been carried out aiming at the isolation of active ingredients from plants used as popular medicines, which have resulted in successful medicines for various aliments. The interest in the use of medicinal plants by governments, industries and institutions has increased the efforts in the research and development of the complementary or alternative medicine $[2,5,6]$. In consequence, studies regarding the biological effect of natural products are extremely important to aid in the better understanding of the action of these isolated chemical substances of phytocomplexes, as well as the extracts obtained from the parts of plants [3,7]. This 
research is of particular importance to the Traditional Chinese Medicine (TCM), particulary due to the sparse quantity of scientific information avaiable.

In the TCM, natural products are used alone or in a formula, as well as in different presentations, as wan or tang [1].

Liu Wei Di Huang Wan (LWDHW) is a magistral formula of the TCM. This herbal mixture is composed of six herbs: Rehmannia glutinosa (rhizomes), Cornus officinalis (fructus), Discorea opposita (rhizomes), Paeonia sufruticosa (root), Alisma orientalis (rhizome) and Poria cocos [8]. According to the TCM, LWDHW is utilized to "tonify the Yin" of the Shen (kidneys) and of the Gan (liver) $[9,10]$. It is also used in the treatment of the asthma and seems to act directly on cytokine gene expression from lymphocytes [8]. Moreover, effects in the aging [11], in the memory activity and in the prevention of neuronal degeneration $[12,13]$ have been associated with use of LWDHW. Authors [14] have reported that this magistral formula does not have a genotoxic action at the proposed dose.

The use of experimental models to study some of the effects of products used in the TCM is desirable. Assays using radionuclides have been utilized successfully in various investigations related with extracts of medicinal formulas [15] or isolated medicinal plant [16].

Technetium-99m $\left({ }^{99 \mathrm{~m}} \mathrm{Tc}\right)$ is currently utilized for diagnostic procedures (Single Photon Emission Computed Tomography-SPECT) in the nuclear medicine [17,18]. Moreover, ${ }^{99 \mathrm{~m}} \mathrm{Tc}$ has been an important tool in various experimental models [16,19-25]. ${ }^{99 \mathrm{~m}}$ Tc-Red blood cells (RBC) are used to get images of the cardiovascular system and, the spleen, on the detection and localisation of gastrointestinal hemorrhages and on the measurement of RBC [26-28]. To obtain ${ }^{99 \mathrm{~m}} \mathrm{Tc}-\mathrm{RBC}$, samples of blood have been treated with stannous chloride $\left(\mathrm{SnCl}_{2}\right)$, as reducing agent, and plasma and blood proteins have been also labeled [17,18,29]. In addition, an experimental model to study the properties of natural products has been developed using the labeling of blood constituents with ${ }^{99 \mathrm{~m}}$ Tc $[16,20,21,30]$.

Effects of synthetic or natural drugs on the labeling of blood constituents have been previously reported [20,24,25, $31,32]$, and, they are often undesirable. The consequences for luck of such information could lead to misdiagnosis and/or the repetition of the examination. The first consequence could be misleading information that can either mask or mimic certain disease symptoms and the second could be an increase in the radiation dose to the patient and staff $[17,33]$. In consequence, an investigation to evaluate the influence of an aqueous extract of Liu Wei Di Huang Wan on the labeling of blood constituents with ${ }^{99 \mathrm{~m}} \mathrm{Tc}$ is desirable and has been the aim of this study.

\section{Material and methods}

The Ethical Committee on Animal Research of the Univer- sidade do Estado do Rio de Janeiro had approved the protocols used in this work (CEA/153/2006).

\subsection{Reagents}

Stannous chloride $\left(\mathrm{SnCl}_{2}\right)$ (Sigma-Aldrich, USA, reference 208256) was used. Commercial dried powder of Liu Wei Di Huang Wan was obtained from capsules (SKL Herbal Scientific and Pharmaceutical Laboratory, Brazil; lot 100111). The experiments were carried within the validity of the product. Considering the information of this manufacturer, the components of this product are Rhizoma Rehmanniae Preparata, Fructus Corni, Rhizoma Dioscoreae, Rhizoma Alismatis, Cortex Mountan Radicis and Hoelen.

\subsection{Preparation of the extract}

The extract was prepared through addition of $0.9 \% \mathrm{NaCl}$ (saline solution) $(10 \mathrm{~mL})$ to $700 \mathrm{mg}$ of the powder. This preparation was vortexed during $1 \mathrm{~min}$ and centrifuged. The supernatant phase was considered as $70 \mathrm{mg} / \mathrm{mL}$ and denominated $100 \%$. This extract was used and diluted to 35 , $17.50,8.75$ and $4.37 \mathrm{mg} / \mathrm{mL}$ with saline.

\subsection{Labeling process}

Anticoagulated (heparine) blood was withdrawn from rats (Wistar, male, age 3 months, 250-350 g) under anesthesia with sodium thiopental $6.7 \%$. Aliquots $(0.5 \mathrm{~mL})$ of whole blood were incubated with the extract $(0.1 \mathrm{~mL}, 1 \mathrm{~h})$ or with saline (control). After this period of time $\mathrm{SnCl}_{2}(0.5 \mathrm{~mL})$ in the concentration of $1.2 \mu \mathrm{g} / \mathrm{mL}$ [23] was added and incubated for another $1 \mathrm{~h}$ (room temperature). Subsequently, $0.1 \mathrm{~mL}$ of ${ }^{99 \mathrm{~m}} \mathrm{Tc}$-sodium pertechnetate $(3.7 \mathrm{MBq} / \mathrm{mL})$, eluted from a ${ }^{99} \mathrm{Mo} /{ }^{99 \mathrm{~m}} \mathrm{Tc}$ generator (Instituto de Pesquisas Energéticas e Nucleares, Comissão Nacional de Energia Nuclear, São Paulo, Brasil) was added and the incubation continued (10 min). These blood preparations were centrifuged and samples of plasma (P) and blood cell (BC) were separated and they $(20 \mu \mathrm{L})$ were also precipitated with $5 \%$ trichloroacetic acid $(1 \mathrm{~mL})$ and soluble fractions (SF) and insoluble fractions (IF) were obtained. The radioactivity in each fraction was determined in a well counter (Gamma Counter, Gamma C-12, DPC Medlab, LA, USA) and the percentage of radioactivity (\%ATI) was calculated. Briefly, the radioactivity present in BC, IF-P and IF-BC was divided, respectively, by the radioactivity in $\mathrm{P}+\mathrm{BC}$, IF-P+SF-P and IF-BC+SF-BC and the values were multiplied by 100 . Statistical analysis was performed using the ANOVA and Tukey post test $(P<0.05)$.

\section{Results}

Table 1 shows the \%ATI in the $\mathrm{P}$ and $\mathrm{BC}$ compartments 
Table 1 Effect of LWDHW extract on the distribution of radioactivity on the plasma and blood cells compartments ${ }^{\text {a) }}$

\begin{tabular}{ccc}
\hline Concentration of the & \multicolumn{2}{c}{ \%ATI } \\
\cline { 2 - 3 } extract $(\mathrm{mg} / \mathrm{mL})$ & $\mathrm{P}$ & $\mathrm{BC}$ \\
\hline 0.00 & $3.52 \pm 1.19$ & $96.48 \pm 1.19$ \\
4.37 & $2.85 \pm 0.94$ & $97.15 \pm 0.94$ \\
8.75 & $4.44 \pm 1.98$ & $95.56 \pm 1.98$ \\
17.50 & $9.94 \pm 3.02$ & $90.06 \pm 3.02$ \\
35.00 & $38.74 \pm 5.20^{*}$ & $61.26 \pm 5.20^{*}$ \\
70.00 & $45.54 \pm 7.38^{*}$ & $54.46 \pm 7.38^{*}$ \\
\hline
\end{tabular}

a) Aliquots of blood from Wistar rats were incubated with LWDHW, after stannous chloride and ${ }^{99 \mathrm{~m}} \mathrm{Tc}$ was added. These aliquots were centrifuged and plasma (P) and blood cells (BC) were separated. The radioactivity was determined and the percentage of radioactivity (ATI\%) was calculated. Statistical analysis was performed using ANOVA with Tukey post test $(P<0.05) * P<0.05$.

isolated from whole blood incubated with LWDHW. The results indicate a significant and strong decrease $(P<0.05)$ in the distribution of the ${ }^{99 \mathrm{~m}} \mathrm{Tc}$ from $96.48 \pm 1.19$ to $54.46 \pm$ 7.38 in the cellular compartment due to the treatment with LWDHW.

Table 2 shows a significant decrease $(P<0.05)$ in the fixation of ${ }^{99 \mathrm{~m}} \mathrm{Tc}$ on IF-BC (blood cells proteins) from $81.11 \pm$ 4.15 to $61.33 \pm 4.74$ due to the treatment with LWDHW.

Table 3 shows a significant and strong decrease $(P<0.05)$ in the fixation of ${ }^{99 \mathrm{~m}} \mathrm{Tc}$ on IF-P (plasma proteins) from 65.91 \pm 2.44 to $13.15 \pm 3.62$ due to the treatment with LWDHW.

\section{Discussion}

Herbal remedies, including traditional herbal formulas, have a strong acceptance in the field of complementary and alternative medicine. The worldwide public use of herbal remedies in conjunction with or as replacements of conventional medicines is increasing [34]. In consequence, it is worthwhile to try to develop experimental models that could

Table 2 Effect of LWDHW extract on the fixation of radioactivity on the insoluble and soluble fractions of blood cells ${ }^{\text {a) }}$

\begin{tabular}{ccc}
\hline Concentration of the & \multicolumn{2}{c}{$\%$ ATI } \\
\cline { 2 - 3 } extract $(\mathrm{mg} / \mathrm{mL})$ & IF-BC & SF-BC \\
\hline 0.00 & $81.11 \pm 4.15$ & $18.89 \pm 4.15$ \\
4.37 & $75.24 \pm 5.23$ & $24.76 \pm 5.23$ \\
8.75 & $78.97 \pm 4.81$ & $21.03 \pm 4.81$ \\
17.50 & $76.73 \pm 4.10$ & $23.27 \pm 4.10$ \\
35.00 & $63.42 \pm 5.55^{*}$ & $36.58 \pm 5.55^{*}$ \\
70.00 & $61.33 \pm 4.74^{*}$ & $38.67 \pm 4.74^{*}$ \\
\hline
\end{tabular}

a) Aliquots of blood from Wistar rats were incubated with LWDHW, after stannous chloride and ${ }^{99 \mathrm{~m}} \mathrm{Tc}$ was added. These aliquots were centrifuged and plasma (P) and blood cells (BC) were separated and precipitated with trichloroacetic acid. Soluble (IF-BC) and insoluble (SF-BC) fractions of cells were separated and counted. The radioactivity was determined and the percentage of radioactivity (ATI\%) was calculated. Statistical analysis was performed using ANOVA with Tukey post test $(P<0.05)$. $* P<0.05$.
Table 3 Effect of LWDHW extract on the fixation of radioactivity on the insoluble and soluble fractions of plasm ${ }^{\text {a) }}$

\begin{tabular}{ccc}
\hline Concentration of the & \multicolumn{2}{c}{$\%$ ATI } \\
\cline { 2 - 3 } extract $(\mathrm{mg} / \mathrm{mL})$ & IF-P & SF-P \\
\hline 0.00 & $65.91 \pm 2.44$ & $34.09 \pm 2.44$ \\
4.37 & $64.47 \pm 4.63$ & $35.53 \pm 4.63$ \\
8.75 & $66.81 \pm 2.75$ & $33.19 \pm 2.75$ \\
17.50 & $51.22 \pm 5.73^{*}$ & $48.78 \pm 5.73^{*}$ \\
35.00 & $22.86 \pm 4.26^{*}$ & $77.14 \pm 4.26^{*}$ \\
70.00 & $13.15 \pm 3.62^{*}$ & $88.85 \pm 3.62^{*}$ \\
\hline
\end{tabular}

a) Aliquots of blood from Wistar rats were incubated with LWDHW, after stannous chloride and ${ }^{99 \mathrm{~m}} \mathrm{Tc}$ was added. These aliquots were centrifuged and plasma (P) and blood cells (BC) were separated and precipitated with trichloroacetic acid. Soluble (IF-P) and insoluble (SF-P) fractions of cells were separated and counted. The radioactivity was determined and the percentage of radioactivity (ATI\%) was calculated. Statistical analysis was performed using ANOVA with Tukey post test $(P<0.05)$. ${ }^{*} P<0.05$.

permit the investigation of the biological effects associated with the chemical compounds present in these products [35]. Furthermore, in general, it is considered that the level of adverse effects of TCM is low in comparison to the Western medicines [36]. A relevant consideration is that the number of experimental models for the study of the various properties related with the herbal medicines used in the TCM is still limited and the development of new and suitable models is thus highly desired. Investigations using radionuclides have been worthwhile to aid the understanding of several biological mechanisms and some of them have been used to study procedures used in the TCM, such as acupuncture $[15,37,38]$.

The studies with natural products are not easy to develop due to the necessity to choose an adequate form of presentation of a product. Sometimes, the chemical determination of a substance in the natural products is not suitable and it is more convenient to use a commercial form that is normally used by individuals. Moreover, these products are submitted to rigorous quality controls in serious companies [39].

Nevertheless, the establishment of in vitro models to try and verify different properties of synthetic and natural products is worthwhile. These models can aid the understanding of the biological effects associated with the use of several of these products $[20,32]$. This statement has a special relevance to the TCM due to the limited scientific information available about several of the products/procedures used in this medical system.

Natural products can alter the labeling of blood constituents with ${ }^{99 \mathrm{~m}} \mathrm{Tc}$ as some authors have previously reported $[15,16,19-21,23,40]$. The labeling of blood constituents could be decreased due to the action of drugs by (i) binding at the same sites on the blood constituents, (ii) direct inhibition (chelating action) of the stannous and pertechnetate ions, (iii) direct oxidation or generation of free radicals that could oxidize the stannous ion, (iv) antioxidant action impeding or decreasing the stannous ion oxidation, and (v) alteration of the plasma membrane structure or modification 
of the transport system of stannous and pertechnetate ions into cells [29, 33,42].

Extracts of Fucus vesiculosus [29], Coffea arabica [42], Mentha crispa [19], Gingko biloba [42], Psidium guajava [20] and Cordia salicifolia [23] have been shown to decrease the labeling of blood constituents with ${ }^{99 \mathrm{~m}}$ Tc. Peumus boldus [43], Sechium edule [44] and Solanum melongena [45] do not alter this labeling process.

In the present study, LWDHW extract was found to be capable to alter the labeling of blood constituents with ${ }^{99 \mathrm{~m}} \mathrm{Tc}$. A significant decrease $(P<0.05)$ has been observed on the distribution of ${ }^{99 \mathrm{~m}} \mathrm{Tc}$ on the blood compartments. A significant decrease $(P<0.05)$ of the fixation of ${ }^{99 \mathrm{~m}} \mathrm{Tc}$ in the insoluble fraction of blood cells with the concentrations of 35 and $70 \mathrm{mg} / \mathrm{mL}$ was also verified. Moreover, a significant decrease $(P<0.05)$ in the fixation of ${ }^{99 \mathrm{~m}} \mathrm{Tc}$ in the insoluble fraction of plasma with the concentrations of 17.5, 35 and $70 \mathrm{mg} / \mathrm{mL}$ was observed. Although several mechanisms are possible, it is suggested that these alterations could be due to the antioxidant properties of the substances present in the aqueous extract of LWDHW. In consequence the ${ }^{99 \mathrm{~m}} \mathrm{Tc}$, as pertechnetate, would not be reduced. This antioxidant effect would be confirmed by the findings described by other authors [8].

Considering the concepts of the TCM, the energies (Qi) of the kidneys and the liver are closely associated with the blood (Xue) (production and storage) $[9,10,46]$. These "empirical properties" could justify the use of the LWDHW to tonefy the Yin of the Shen (kidneys) and of the Gan (liver). Moreover, the findings reported in our work would justify the use of the LWDHW in the TCM. Similar findings were reported by other authors [15] that have observed an alteration on the fixation of the ${ }^{99 \mathrm{~m}} \mathrm{Tc}$ in blood constituents with a magistral formula (Buzhong Yi Qi Wan) that is used to tonify the blood. Putting together these explanations, it is attractive to suppose that it is possible to integrate the concepts of both Western and Eastern Medicines.

In conclusion, the results suggest that the substances present on this extract would alter the blood labeling process, probably due to (i) redox properties (antioxidant and chelator activities) and/or (ii) specific actions in the bindings sites where the ${ }^{99 \mathrm{~m}} \mathrm{Tc}$ would be bound on the blood constituents. In consequence, it is suggested precaution on the interpretations of nuclear medicine results that have been performed with blood constituents labeled with ${ }^{99 \mathrm{~m}} \mathrm{Tc}$ in patients that are undertaking LWDHW.

This work was supported by Fundação de Amparo à Pesquisa do Estado do Rio de Janeiro (FAPERJ), Universidade do Estado do Rio de Janeiro (UERJ), Conselho Nacional de Pesquisa e Desenvolvimento (CNPq) and Instituto Nacional do Câncer (INCa).

1 Rotblatt M, Ziment I. Evidence-Based Herbal Medicine. Philadelphia: Hanley \& Belfus, 2002

2 Saba A B, Oyagbemi A A, Azeez O I. Antidiabetic and haematinic effects of Parquetina nigrescens on alloxan induced type-1 diabetes and normocytic normochromic anaemia in Wistar rats. Afr Health Sci, 2010, 10: 276-283

3 Firenzuoli F, Gori L, Neri D. Clinical phytotherapy: Opportunities and problematic. Ann Ist Super Sanita, 2005, 41: 27-33

4 Licciardi P V, Underwood J R. Plant-derived medicines: A novel class of immunological adjuvants. Int Immunopharmacol, 2011, 11: 390-398

5 Suzuki N. Complementary and alternative Medicine: A Japanese perspective. Adv Accounts Publ, 2004, 1: 113-118

$6 \mathrm{Fu}$ J, Sun X, Wang J, et al. Progress in quantitative analysis of plant hormones. Chin Sci Bull, 2011, 56: 355-366

7 Botsaris A S. Fitoterapia Chinesa e Plantas Brasileiras. ed. 2. Ícone: São Paulo, 2002

8 Shen J J, Lin C J, Huang J L, et al. The effect of Liu Wei Di Huang Wan on cytokine gene expression from human peripheral blood lymphocytes. Am J Chin Med, 2003, 31: 247-257

9 Yu C S, Fei L. Guia Clínico de Ervas e Fórmulas na Medicina Tradicional Chinesa, $1^{\mathrm{a} e d}$, São Paulo: Roca, 1996

10 Zhufan X, Jiazhen L. Medicina Interna Traditional Chinesa: Diabetes

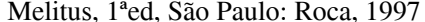

11 Kang D G, Sohn E J, Moon M K, et al. Yukmijihwang-tang ameliorates ischemia/reperfusion-induced renal injury in rats. J Ethnopharm, 2006, 104: 47-53

12 Wei X L. Studies on learning and memory function-related genes in the hipocampus and the relationship between the cognitive enhancing effect of liuwei dihuang decoction (LW) and gene expression. Sheng Li Ke Xue Jin Zhan, 2000, 31: 227-230

13 Rho S W, Kang M K, Choi B O, et al. Effects of Yukmijihwang-tang derivatives (YMJD), a memory enhancing herbal extract, on the geneexpression profile in the rat hippocampus. Biol Pharm Bull, 2005, 28 : 87-93

14 Hyekyung H, Jun Kyoung L, Ho Young L, et al. Evaluation of genotoxicity of Yukmijihwang-tang, a herbal formula. Regul Toxicol Pharm, 2011, 59: 391-396

15 Giani T S, Paoli S, Presta G A, et al. An extract of a formula used in the traditional Chinese medicine (Buzhong Yi Qi Wan) alters the labeling of blood constituents with technetium-99m. Braz Arch Biol Technol, 2007, 50: 111-116

16 De K, Chandra S, Misra M. Assessment of the effect of Bacopa monnieri (L.) Wettst. Extract on the labeling of blood elements with technetium-99m and on the morphology of red blood cells. Braz J Pharmacogn, 2009, 19: 664-671

17 Hladik III W B, Saha G B, Study K T. Essentials of Nuclear Medicine Science. Sidney: Williams and Wilkins, 1987

18 Saha G B. Fundamentals of Nuclear Pharmacy, New York: SpringerVerlag, 2010

19 Santos-Filho S D, Diré G L, Lima E, et al. Effect of Mentha crispa (mint) Extract on the labeling of blood elements with technetium99m: A possible evaluation of free radicals. J Biol Sci, 2004, 4: 266-270

20 Abreu P R, Almeida M C, Bernardo R M, et al. Guava extract (Psidium guajava) alters the labeling of blood contituents with tecnetium99m. J Zhejiang Univ Sci B, 2006, 6: 429-435

21 Moreno S R F, Silva A L S, Diré G, et al. Effect of oral ingestion of an extract of the herb Uncaria tomentosa on the biodistribution of sodium pertechnetate in rats. Braz J Med Biol Res, 2007, 40: 77-80

22 Madar I, Ravert H, DiPaula A, et al. Assessment of severity of coronary artery stenosis in a canine model using the PET agent $18 \mathrm{~F}$ fluorobenzyl triphenyl phosphonium: Comparison with ${ }^{99 \mathrm{~m}} \mathrm{Tc}-\mathrm{Tetro}-$ fosmin. J Nucl Med, 2007, 48: 1021-1030

23 Frydman J N, Rocha V C, Benarroz M O, et al. Assessment of effects of a Cordia salicifolia extract on the radiolabeling of blood constituents and on the morphology of red blood cells. J Med Food, 2008, 11: 767-772

24 Bustani H, Colavolpe C, Imbert-Joscht I, et al. Chocolate intake associated with failed labeling of ${ }^{99 \mathrm{~m}} \mathrm{Tc}$ red blood Cells. J Nucl Med Technol, 2009, 37: 107-110

25 Holanda C M, Silva-Júnior M F, Barbosa V S, et al. The effect of the 
Rochagan on Radiolabeling with (99m)Tc. Cell Mol Biol, 2009, 55: 23-28

26 Early P J, Sodee D B. Principles and Practive of Nuclear Medicine. 2nd ed. London: Mosby Year Book, 1996

27 Wong K T, Beauvais M M, Melchior W R, et al. Enhanced liver uptake of Tc-99m-labeled RBCs during gastrointestinal bleed scintigraphy using transfused RBCs compared with autologous RBCs. Clin Nucl Med, 2004, 29: 522-523

28 Verdu J, Martinez A, Anton M A, et al. Increased thallium-201 uptake and Tc-99m red blood cell accumulation in hemangioma. Clin Nucl Med, 2005, 30: 25-26

29 Olds G D, Cooper G S, Chak A, et al.The yield of bleeding scans in acute lower gastrointestinal hemorrhage. J Clin Gastroenterol, 2005, 39: $273-277$

30 Fernandes J F O, Brito L C, Santos-Filho S D, et al. An aqueous extract of Pfaffia sp. does not alter the labeling blood constituents with technetium-99m and the morphology of the red blood cells. Braz J Pharmacogn, 2005, 15: 126-132

31 Oliveira J F, Oliveira M B, Ávila A S, et al. Assement of the effect of Fucus vesiculosus extract on the blood constituents with technetium-99m and the histological modifications on the shape of the red blood cells. Food Chem Toxicol, 2003, 41: 15-20

32 Fonseca A S, Frydman J N, Rocha V C, et al. Acetylsalicylic acid decreases the labeling of blood constituents with technetium- $99 \mathrm{~m}$. Acta Biol Hung, 2007, 58: 187-198

33 Bernardo-Filho M, Santos-Filho S D, Moura E G, et al. Drug interaction with radiopharmaceuticals: A review. Braz Arch Biol Technol, 2005, 48: 13-27

34 Firenzuoli F, Gori L. Herbal Medicine Today: Clinical and Research Issues. Evid Based Compl Alter Med, 2007, 4: 37-40

35 Halberstein R A. Medicinal Plants: Historical and cross-cultural usage patterns. Ann Epidemiol, 2005, 15: 686-699

36 Hosbach I, Neeb G, Hager S, et al. In defense of traditional Chinese herbal medicine. Anesthesia, 2003, 58: 282-283

37 Souza D E, Souza R S S, Manoel C V, et al. M. Acupuncture stimu- lation at Taixi Point: Effect on Technetium-99m methylenediphosphonate bioavailability in rats. Med Acupunct, 2011, 23: 93-99

38 Senna-Fernandes V, França D L, Santos K C, et al. Effect of Zusanli (ST.36) electroacupuncture at two frequencies on the bioavailability of $(99 \mathrm{~m}) \mathrm{Tc}$-sodium pertechnetate and on labeling of blood constituents in rats. J Acupunct Meridian Stud, 2009, 2: 135-146

39 Chaudhary M I, Qing H, Xiao G P, et al. Clematis huchounsis Tamura: A traditional Chinese herbal medicine and its quality control using a high performance liquid chromatography technique. Biol Pharm Bull, 2007, 30: 165-168

40 Mousinho K C, Correia M B L, Barros A L S, et al. Avaliação do controle radioquímico do Ricinus communis L. e Tc-99m na marcação de hemácias. Braz J Pharmacogn, 2009, 19: 449-451

41 Oliveira J F, Santos-Filho S D, Catanho M T J A, et al. Effect of extract of medicinal plants on the labeling of the elements with technetium-99m and on the morphology of red blood cells (RBC): Toxicological actions of roast coffee beans (Coffea arabica). Indian J Nucl Med, 2003b, 18: 52-56

42 Moreno S R F, Freitas R S, Rocha E K, et al. Protection of plasmid DNA by a Ginkgo biloba extract from the effects of stannous chloride and the action on the labeling of blood elements with technetium-99m. Braz. J Med Biol Res, 2004, 37: 267-271

43 Reineger I W, Silva C R, Felzenszwalb I, et al. Boldine action against the stannous chloride effect. J Ethnopharmacol, 1999, 68: 345-348

44 Diré G, Gomes M L, Lima E A C, et al. Effect of Sechium edule extract of the Biochemical determination and on molecular and cellular levels. Pak J Biol Sci, 2004, 4: 146-150

45 Carmo F S, Diniz C L, Pereira M O, et al. Characterization of physicochemical parameters and the effect on the labeling of blood constituents with technetium-99m of a Solanum melongena commercial extract. J Med Plants Res, 2011, 5: 5598-5604

46 Chen Y, Kang Z, Yan J, et al. Liu Wei Di Huang Wan, a well-known traditional Chinese medicine, induces CYP1A2 while suppressing CYP2A6 and $\mathrm{N}$-acetyltransferase 2 activities in man. J Ethnopharmacol, 2010, 132: 213-218

Open Access This article is distributed under the terms of the Creative Commons Attribution License which permits any use, distribution, and reproduction in any medium, provided the original author(s) and source are credited. 